\title{
PRODUÇÃO ACADÊMICA FEMININA EM TEMPOS DE PANDEMIA DO COVID-19
}

\author{
Leticia Prazeres Falcão ${ }^{1}$ \\ Camila Fechine Machado
}

\section{RESUMO}

A COVID 19 atingiu setores sociais e em especial, a educação. Frente a paralisação de aulas, o ensino jurídico precisou avaliar questões importantes da sua formação. A participação feminina na produção acadêmica gira em torno do debate visto que se fala de um número grande na academia, mas pouco valorizado. $O$ contexto que a figura e produção feminina estão inseridas, o isolamento social, acúmulo de papéis e trabalho remoto interferem nesse exercício. Tal concatenação visa entender como é a produção feminina acadêmica em tempos pandêmicos. A metodologia se dá em formatos bibliográficos e descritivos dentro de leitura indutiva.

Palavras-chave: Mulher; Produção Acadêmica; COVID-19; Ensino jurídico; Pandemia

\section{FEMALE ACADEMIC PRODUCTION IN TIMES OF COVID-19 PANDEMIC}

\begin{abstract}
COVID 19 reached social sectors and, in particular, education. Faced with the interruption of classes, legal education needed to assess important issues in their training. The female participation in academic production revolves around the debate since there is talk of a large number in the academy, but little value. The context in which the female figure and production are inserted, social isolation, accumulation of roles and remote work interfere in this exercise. Such concatenation aims to understand how female academic production is in pandemic times. The methodology takes place in bibliographic and descriptive formats within inductive reading.
\end{abstract}

Keywords: Woman; Academic production; COVID-19; Legal education; Pandemic

\section{INTRODUÇÃO}

O advento da pandemia de COVID-19 no mundo impactou toda a sociedade global, mobilização de sistemas de saúde, ações estratégicas governamentais, corridas em laboratórios, paralisação de atividades e o isolamento social foram algumas das tantas outras intervenções que precisaram ser realizadas. Embora não seja inédito na história humana o

\footnotetext{
${ }^{1}$ Mestranda em Processo e Direito ao Desenvolvimento da Unichristus

${ }^{2}$ Mestranda em Processo e Direito ao Desenvolvimento da Unichristus
} 
lidar com uma pandemia em grandes proporções, para muitas gerações o fato é novo e chegou para questionar e incitar uma reflexão de que até onde tudo o que se conhece é realmente suficiente para tratar com o imprevisível.

Um dos setores mais afetados com a suspensão das atividades foi sem dúvida a educação, em razão da fácil e rápida propagação do vírus, a aglomeração "natural" de salas de aula acabaria sendo um vetor de contaminação muito intenso. A educação como um todo, em todos os setores de níveis básico, fundamental, média e superior precisou para além uma medida sanitária de afastamento, viu-se diante de novos desafios nos quais até onde o ensino poderia ou deveria realmente parar.

A palavra adaptação nunca foi tão utilizada para simbolizar uma releitura urgente de metodologias, exposições, relação docente-discente, gestões e inserções de tecnologia. Por óbvio, em cada país, cada escola, universidade, aluno e professor possui uma realidade particular que o ajuda ou agrava situações de circunstâncias de desigualdades, entretanto o que se faz de certa forma de maneira consensual é que a educação em si nunca precisou ser tão reavaliada como hoje (COELHO, 2020).

As peculiaridades do ensino jurídico brasileiro também escancaram as mazelas e os obstáculos que a educação no país perpassa. Para além das diferenças nas infraestruturas de universidades e faculdades públicas e privadas, existe também a diferença em como essa tecnologia de implementação de aulas remotas é instalada e quando seriam instaladas. Não se trata apenas de um discurso sobre equipamentos e redes de conexão, mas o lidar e obtenção dessa tecnologia em tempos de uma sociedade de informação, não configura a mesma em todos os lugares (SANTOS, 2020). Esse acesso não é o mesmo, assim como seus operadores também não são, o que a realidade da pandemia ensina? Os percalços do ensino jurídico no Brasil são reflexos de uma cultura pós colonial que se arrasta nas viradas de anos e encontram na paralisação advinda da COVID-19 uma constatação: as desigualdades nunca foram tão evidentes.

Nesse sentido, relevante se faz avaliar a conjuntura a qual a educação e por conseguinte o ensino jurídico perpassaram e ainda perpassam em meio à pandemia de COVID-19, levando em consideração tanto o implemento das aulas remotas, utilização de tecnologias para otimizar aulas e projetos, como também alertar para particularidades da educação jurídica de ensino superior que revelam ainda um tendência presa às estigmas passados. Não que isso represente a sua totalidade, visto que já há movimentos de reinvenção 
desse ensino levando em conta quem são os sujeitos envolvidos: docentes, discentes, universidades, gestores.

Se para conhecer o ambiente, se faz interessante entender seus sujeitos, partindo desse pressuposto se avalia como se dá a participação feminina na produção acadêmica, de que modo essa presença é tida perante a comunidade educacional e o que ela representa dentro e fora dos muros das universidades. Em verdade, esse recorte revela muito mais do que um olhar no tocante ao exercício acadêmico, destaca o que é ser uma docente ou pesquisadora em país ainda marcado por uma divisão sexista do trabalho e de produção.

De modo a concatenar as ideias apresentadas, deve ser levado em consideração que como se deu e está ocorrendo a produção acadêmica feminina diante do isolamento social e vias remotas de trabalho. Em razão da multiplicidade de tarefas, dentre elas, as domésticas, o home schooling, as relacionais e maternas, fora ascendida um alerta que parece evidenciar não só a capacidade de superação e resiliência nesses tempos, como demonstrou como a estratificação de papéis e de tratamento feminino ainda é algo que impacta não só no desempenhar de atividades, como demonstra uma luta maior no que diz respeito ao reconhecimento e valorização dessas profissionais universidades à fora.

Como suporte metodológico, a pesquisa possui tanto embasamento bibliográfico como descritivo, quando se utilizou da aplicação de formulário para coleta de dados no que diz respeito à produção acadêmica feminina em tempos de COVID-19. A lógica apresenta é indutiva visto que parte de premissas particulares para se chegar a uma análise e entendimento mais amplo sobre os fatores que interferem direta ou indiretamente nessa produção.

\section{PANORAMA DO ENSINO JURÍDICO SUPERIOR NO BRASIL EM TEMPOS DE PANDEMIA DO COVID-19}

Desde o dia 11/03/2020, momento em que a Organização Mundial da Saúde (OMS) anunciou o estado de pandemia em virtude do vírus covid- $19^{3}$, as preocupações sociais, econômicas, políticas e jurídicas tornaram-se evidentes.

Embora o surto do covid-19 seja um problema inicialmente de saúde pública, a educação brasileira sente impactos. Nesse cenário global de preocupações, o direito e a

\footnotetext{
${ }^{3}$ Devido à disseminação rápida do coronavírus, a OMS "elevou o estado da contaminação pelo novo coronavírus como pandemia. Fonte: https://agenciabrasil.ebc.com.br/geral/noticia/2020-03/organizacao-mundial-da-saudedeclara-pandemia-de-coronavirus
} 
educação, enquanto ciência social, não foram imune aos impactos causados pelo novo corona vírus, tendo em vista os desafios enfrentados pelo ensino jurídico nesse momento atípico.

Assim, foi editada a Lei $\mathrm{n}^{\circ} 13.979$, de 6 de fevereiro de 2020, que "dispõe sobre as medidas para enfrentamento da emergência de saúde pública de importância internacional decorrente do coronavírus responsável pelo surto de 2019” (BRASIL, 2020). Posteriormente, a medida provisória $\mathrm{n}^{\circ} 926$, de 20 de março de 2020 e a Lei $\mathrm{n}^{\circ} 14.006$, de 28 de maio de 2020, trouxeram algumas alterações.

Dentre das ações previstas a serem tomadas, estão o distanciamento social, a quarentena e determinação de realização compulsória de exames médicos (BRASIL, 2020). Não obstante o mundo já tenha passado por alguns momentos pandêmicos

\footnotetext{
"Hoje, a humanidade enfrenta uma crise aguda não apenas por causa do coronavírus, mas também pela falta de confiança entre seres humanos. Para derrotar uma epidemia, as pessoas precisam confiar nos especialistas, os cidadãos precisam confiar nos poderes públicos e os países precisam confiar uns nos outros." (HARARI, 2010, POSIÇÃO 100)
}

Assim como inúmeros outros setores, a educação sofreu fortes perturbações em virtude do isolamento social gerado pela pandemia do covid-19. Nesse cenário, o ensino jurídico recebe destaque, tendo em vista que nesse momento, o Brasil é hoje o país com mais cursos de Direito do que todos os outros países reunidos. São aproximadamente 1.200 cursos jurídicos autorizados no país hoje ${ }^{4}$.

É visível que atualmente, apesar de já existirem algumas regras de flexibilização em determinados Estados, todos ainda se deparam com diretrizes de Direito Temporário no tocante à suspensão das aulas, atividades compensatórias, ensino remoto ou híbrido, adaptação de carga horária e a substituição ou protelação de tarefas de cunho mais prático. Geralmente as condutas de gestão e coordenações de curso seguem revisões constantes a depender da situação epidemiológica da localidade, há a conversa com autoridades e a

\footnotetext{
4 "Brasil tem mais faculdades de Direito do que todos os países no mundo, juntos. Existem 1.240 cursos para a formação de advogados em território nacional enquanto no resto do planeta a soma chega a 1.100 universidades. Os números foram informados pelo representante do Conselho Federal da Ordem dos Advogados do Brasil (OAB) no Conselho Nacional de Justiça (CNJ), o advogado catarinense Jefferson Kravchychyn." Fonte: https://www.oabpr.org.br/brasil-tem-mais-faculdades-de-direito-que-todos-os-paises/
} 
necessidade de mesmo em permissão de ensino híbrido, que haja toda uma adaptação das instalações de acordo com as normas sanitárias (RODRIGUES, 2020).

Ao que parece, em muito já se alertava para a real necessidade de alinhamento entre o Direito e a realidade social, de modo que demandas e respostas pudessem ter algum nível de equiparação. Voltar os olhos para o ensino jurídico em tempos de pandemia, é mais do que nunca iniciar ou continuar cursos jurídicos dentro de um "novo normal", mas formatar o ensino em si, conhecer seu público, a realidade dos docentes e os óbices sociais e estruturais inerentes do sistema educacional brasileiro.

No Brasil, nas faculdades de Direito, ainda predominava um grande preconceito sobre o ensino à distância. $\mathrm{A} \mathrm{OAB}$ já se manifestou diversas vezes resistência contra um ensino jurídico totalmente virtualizado ${ }^{5}$. Ainda não se tem a aprovação de cursos inteiramente online, de forma que apenas $40 \%$ do curso pode se dar nessa modalidade, de acordo com a portaria $1428^{6}$.

Ocorre com o distanciamento social que foi imposto, as aulas presenciais foram proibidas e professores, de repente, tiverem que se adaptar ao formato online de aulas, mesmo sem nunca ter ministrado uma aula nesse novo formato.

A alternativa do ensino jurídico por via remota colocou em evidência até onde a cultura de um ensino jurídico tradicional ${ }^{7}$, mais expositivo e com distanciamento entre alunos e professores é ou não viável nessa nova modalidade de lecionar. Isso acontece visto que o formato das aulas com certa hierarquização do ensinar-aprender, metodologias ainda muito direcionadas em um sentido único de conhecimento e pouco atrativas, por exemplo, esbarram

\footnotetext{
5 “OAB vai à justiça contra graduações a distância em Direito" Fonte: https://www.oab.org.br/noticia/57702/oabvai-a-justica-contra-graduacoes-a-distancia-em-direito.

${ }^{6}$ Art. $3^{\circ}$, Portaria ${ }^{\circ} 1.428$, de 2018: O limite de $20 \%$ (vinte por cento) definido art. $2^{\circ}$ poderá ser ampliado para até $40 \%$ (quarenta por cento) para cursos de graduação presencial, desde que também atendidos os seguintes requisitos:

I - a IES deve estar credenciada em ambas as modalidades, presencial e a distância, com Conceito Institucional CI igual ou superior a 4 (quatro);

II - a IES deve possuir um curso de graduação na modalidade a distância, com Conceito de Curso - CC igual ou superior a 4 (quatro), que tenha a mesma denominação e grau de um dos cursos de graduação presencial reconhecidos e ofertados pela IES;

III - os cursos de graduação presencial que poderão utilizar os limites definidos no caput devem ser reconhecidos, com Conceito de Curso - CC igual ou superior a 4 (quatro); e

IV - A IES não pode estar submetida a processo de supervisão, nos termos do Decreto n ${ }^{\circ} 9.235$, de 2017, e da Portaria Normativa $\mathrm{MEC}^{\circ} 315$, de 4 de abril de 2018.

7 "A racionalização da ciência, ao separar o objeto de seu ambiente, bem como do sujeito pensante que o observava, cria um ideal de ciência que, no Direito, se reflete na elaboração e aplicação de leis duras, assepsiadas de todo valor subjetivo e social" (RAMALHO, 2019, p. 32).
} 
no ambiente tecnológico um verdadeiro desafio de até onde abandonar o confortável significa também o permitir um Direito mais adaptável.

Fato é que o ensino jurídico no Brasil ainda é centralizado em aulas unicamente expositivas, embora já tivemos alguns avanços significativos.

\subsection{O ENSINO PARTICIPATIVO A PARTIR DO USO DE TECNOLOGIAS}

Com o isolamento social e parte das universidades mantendo os cursos em via remota, parece que tenha se chegado a um momento oportuno de também crítica do ensino jurídico em si, muito se olha para dentro dos muros das faculdades e pouco se olha para fora, para quem de fato são os alunos e professores, por exemplo. Isto é levantado visto que a realidade de cada um influencia diretamente na possibilidade ou não de acesso às aulas, ao material, a uma internet e conexão de qualidades, acaba interferindo nas escolhas pedagógicas e metodológicas que esse docente vai levantar, importa na própria dinâmica do trabalho e estudo em caráter de home office, que precisa de alguma forma estar em sintonia com os demais papéis que as pessoas exercem em suas residências.

O aluno e o professor não simbolizam perfis exclusivos em todo o país, o ensino jurídico nesse contexto de operacionalidade precisa se lembrar quem faz parte desse canal de comunicação e aproximar as necessidades das ofertas. Até pelo fato de que são essas escolhas ${ }^{8}$ políticas feitas em um primeiro momento pelos professores, mas com atuações de coordenadores e gestores, que acabam direcionando de maneira direta ou indiretamente o desenvolvimento de habilidades, formação de senso crítico e a construção de autonomia (GHIRARDI, 2012).

As metodologias ativas de ensino jurídico não são fórmulas prontas que podem ser facilmente replicadas, mas são ferramentas que podem ser utilizadas pelo professor, para envolver mais o aluno no processo de aprendizagem. Assim, se faz necessário que o docente

\footnotetext{
${ }^{8}$ As escolhas no ensino jurídico são de extrema relevância visto que de alguma forma elas influenciam em um acesso material e formal de Justiça. Concepção que já não se pode mais reduzir ao acesso de um sistema, tribunais e burocracia, mas um acesso que diga respeito aos seus operadores, a quem aplica, a quem dialoga, a quem intermedia Direito e outras searas, a quem se permite conhecer outras formas de conhecimento. O acesso à Justiça contemporâneo também possui seu embrião nas salas de aulas, sejam elas presenciais ou remotas, a troca inerente de um processo de educação em algum momento será responsável pelos direcionamentos dos caminhos possíveis dentro de uma sociedade (CARDOSO, 2007).
} 
tenha estratégias de implementação para cada metodologia que pretende adotar. A principal delas é conhecer seu grupo de alunos, suas habilidades e dificuldades (GHIRARDI, 2012).

Assim, o aluno passa a ser a pessoa chave na sala de aula, e não o professor. A ideia de protagonismo do aluno permite que cada aluno construa seu caminho de aprendizagem e consiga aliar a teoria à prática (GHIRARDI, 2012). É interessante que o aluno seja instigado a aprimorar sua capacidade de reflexão e seu senso crítico.

Os alunos aprendem ou aprendem melhor quando participam efetivamente das aulas, quando conseguem aplicar a teoria ao dia-a-dia, quando interpretam um papel de algum profissional do direito, enfim, quando estão envolvidos ativamente no processo de aprendizagem.

Ocorre que com a implementação de tecnologias no ambiente virtual, a aplicação desses métodos participativos revelou-se ainda mais de difícil aplicação, pela dificuldade de controle da participação, perda de contato visual já que muitos alunos deixavam as câmeras desativadas, problemas de acesso à internet, falta de habilidade com as ferramentas tecnológicas, dentre outros.

A tecnologia não pode ser encarada enquanto vilã do ensino jurídico mais conhecido, o permitir dessa ingerência implica não só na otimização de tempo e espaço, como também possibilita a interseccionalidade de outras searas que não a do Direito. Exige do corpo de professores, coordenadores e gestores a parceria com profissionais de sistemas de informação, engenharia de software, ciência de dados, sugerem aos alunos posturas mais ativas e autônomas nesse novo espaço, o pensar em metodologias participativas por meio de plataformas, gamificação e interações pelas telas. O que já era algo meio que inerente das geração de muitos discentes, passa a participar não só de momentos de lazer, mas a tecnologia parece ter chegado pra ficar em um ensino jurídico que clama urgentemente por um (re)pensar e por um novo permitir (FEFERBAUM; LIMA, 2020).

O calendário de aulas foi mantido: mesmo dia e mesma hora, só que por computador. No entanto, com o passar das semanas, alunos e alunas começam a expressar um certo cansaço das telas e das longas aulas, já que o impacto do tempo é diferente presencial e virtualmente. Em meio à exceção que estamos vivendo, a continuidade das aulas traz diversas questões de outras ordens sobre a vida, as prioridades e a sobrevivência: qual é o papel das aulas neste momento? Devemos manter o cronograma a qualquer custo? Proporcionar apenas a continuidade de uma rotina? Vamos ver o que aprendemos (FEFERBAUM; KLAFKE, 2020) 
Assim, a pandemia possibilitou ainda a ressignificação do papel da sala de aula. Como ocupar melhor esse espaço físico da aula, que compense o aluno deslocar-se, despender tempo e dinheiro, ao invés de apenas ligar o computador e assistir as aulas?

Nesse ponto, as metodologias ativas precisam ainda mais ser aprimoradas, já que o formato online distancia o aluno do professor, bem como dos demais colegas.A implementação de métodos participativos no ensino jurídico no formato remoto tornou-se um desafio ainda maior. Afinal, como instigar o protagonismo do aluno, se a maioria deles sequer ativaram a câmera durante a aula?

Desse paradigma de reinvenção dos professores, priorizar atividades interativas nos encontros síncronos, estabelecer uma integração mais dinâmica, estimular a participação dos alunos, propor intervalos, solicitar feedbacks das turmas, são algumas das atitudes que poderiam ser utilizadas pelos docentes e a coordenação.

Em face da multiplicidade de métodos e ferramentas, como estudos de casos, debates, leituras, seminários, design thinking, kahoot, role play, google forms, mentimenter, as aulas poderiam ser mais dinâmicas e atrativas.

A importância de enfatizar o protagonismo do aluno e de garantir a humanização desse espaço de aprendizagem são também relevantes no espaço presencial, mas esse momento é ideal para reforçar esses pilares, principalmente em face das especificidades de cada aluno e aluna.

Sabe-se que existe uma grade curricular para ser seguida e um conteúdo programático para ser lecionado, mas existem fenômenos ou situações que em decorrência da pandemia e afastamento social ganharam destaque como a telemedicina, o aumento no número de divórcios, relações de consumo em ambiente virtual, proteção de dados sensíveis e a utilização de meios autocompositivos para driblar a morosidade judicial. São questões que pedem desse docente um olhar mais atento para não tratar como mera consequência e sim como um conjunto de fatores jurídicos, sociais, políticos e econômicos que trazem essa roupagem desafiadora dentro do ensino jurídico (DA GAMA, 2020).

Nesse cenário, questiona-se: será que a pandemia veio pra alterar esse paradigma de que o formato on-line não funciona? Nesse processo de reinvenção do ensino jurídico, as mulheres foram ainda mais impactadas, tendo em vista a dificuldade de conciliar as tarefas domésticas e o home office. 


\section{A PRESENÇA FEMININA NA PRODUÇÃO ACADÊMICA}

O caminho pelo qual a mulher vem percorrendo dentro das universidades e faculdades brasileiras, diz respeito à uma luta que começa desde ao direito da mesma estudar e se formar, até o de adentrar nessas instituições em diversos cargos e não só realizar suas funções com grande qualidade, como também servir de exemplo para toda uma geração. Seja no tocante ao exercer da docência, no desenvolver de projetos ou no administrar de gestões educacionais, certo é que essas posições refletem mais do que uma causa que envolve respeito e um equilíbrio no tocante aos privilégios masculinos, mas também estão conectadas com seus espaços e lugares de fala.

A produção de conhecimento acadêmico é antiga e em grande parte da história, foi direcionada e aclamada pelas vozes e presenças masculinas. Não quer dizer que a mulher nunca produziu, mas apenas recentemente começou a ocorrer a conquista e oportunidade dessas profissionais contribuírem e inovarem com a ciência. As mulheres cientistas precisam ser encaradas enquanto sujeitos em toda sua magnitude, de modo que entender as suas produções é ter um olhar amplo sobre o contexto situacional laboral e uma espécie de intersecionalidade de outras funções que as mesmas exercem (SANTOS, 2016).

Ser produtiva nesse espaço de pesquisa, é uma das formas de sair ou pelo menos atenuar a invisibilidade que é posta para a figura feminina, para além de fazer jus aos requisitos e demandas frentes aos órgãos que regulam as publicações por exemplo, é uma maneira de compartilhar conhecimento e de fazer valer o empenho no manuseio de investigações. Ser produtiva é uma constante que caminha junto com negociações que giram em torno de funções familiares, domésticas, relacionais e sociais que fazem parte dessa "carga" cobrada (SANTOS, 2016).

Esses avanços caminham da quebra de algumas posturas discriminatórias quando se é levantado que algumas áreas como as de exatas ou tecnologia não seriam do "perfil feminimo", de que as humanas ou sociais seriam mais propensas visto o lidar com pessoas, a necessidade de cuidado e afeto. Não se quer dizer que tais relações não possam fazer sentido em algum ponto, mas a atribuição medida em uma suposta incapacidade é um dos óbices que dificulta todo o mérito conquistado pelas mulheres no espaço acadêmico. Tanto é que quando alguma se destaca por alguma pesquisa produzida, logo se torna referência não só pela 
investigação em si, como também por ter alcançado tal descoberta e ser mulher (MALCOM, 2006).

A cultura que ainda permeia grande parte do exercer científico é pautada em padrões masculinos e sexistas e servem a todo tempo de obstáculos a serem superados. O próprio ritmo de produção e o exercer competitivo, mais típico de modelos direcionados a homens cientistas na academia, é posto como o que deve ser buscado para uma mulher atinja as metas e objetivos estipulados por instituições e projetos, por exemplo. $\mathrm{O}$ ambiente acadêmico ainda possui traços elitistas que segregam e excluem sujeitos que historicamente buscam respeito e reconhecimento de direitos, é quase que como uma luta contra a hegemonia em um espaço no qual a diversidade deveriam imperar, claro que isso não representa a totalidade dessa configuração, mas ainda diz respeito a núcleos que insistem em perpetuar esse sistema (SILVA, 2013).

\footnotetext{
Mesmo com a inserção das mulheres na ciência, ainda persiste a divisão sexual do trabalho, o que resulta na constituição de carreiras diferentes para homens e para mulheres. Ao analisar as trajetórias dessas mulheres na ciência, percebi que elas foram, de alguma forma, levadas a se adaptar ao "modelo masculino" de pensar e fazer ciência, não apenas para serem consideradas cientistas, mas também para serem bem-sucedidas na profissão (SILVA, 2013, p. 10-11).
}

Talvez a concepção de que as mulheres conseguem realizar diversas atividades ao mesmo tempo, seja algo que corrompe a delegação de algumas responsabilidades. De fato, essa escalada ainda patriarcal e hierarquizada dentro de muitos espaços sobrecarrega muitas docentes e pesquisadoras que realizam seus projetos não exclusivamente enquanto encargos, mas porque os mesmos representam sonhos. Sonhos de constituírem novos debates, levar discussões para o campo acadêmico e problematizar questões naturalizadas ou não exploradas, incomodar positivamente levantamento questões que envolvam descobertas, ineditismos e reconhecimento.

Nota-se que a presença feminina na produção acadêmica, assim como na ciência em geral, não se resume apenas na inserção ou não das mulheres nessa conjuntura, a provocação engloba as estruturas tradicionalmente postas nesses mesmos espaços de diálogo. Gênero e ciência representa um estudo também antropológico e sociológico das escaladas de posições e modelos sobrepostos. Não são apenas as áreas escolhidas, os seletivos prestados, a forma de produção e a postura adotada, mas também configuram alicerces dessa constante luta o alerta 
para uma problemática de muito mais profundidade do que realmente se pensa (KOVALESKI, 2013).

Ainda neste ponto, o modelo masculino de presença acadêmica ainda reflete em uma espécie de modelo paralelo no tocante à carreira dessas mulheres que tentam se inserir nesse universo (VELHO, 2006). Por vezes, existe uma sobreposição de cargos nas universidades, por exemplo, em que há a falsa crença de algumas matérias a serem lecionadas ou administradas, devem ser dirigidas à professoras, visto terem um "tato mais sensível" para as temáticas, novamente, isto não representa a generalidade de casos e nem se questiona a competência dos profissionais envolvidos. A questão é qual o motivo, por trás de justificativas de disponibilidade, carga horária, currículo e experiência, as cadeiras de Direito de Família e Infância e Juventude são geralmente associadas ou postas para mulheres atuarem?

O próprio debate sobre relações de gênero nos espaços acadêmicos, só passou a ser possível a partir do ingresso das mulheres em universidades, para além da demonstração do chamado lugar de falar, têm-se em verdade entre as décadas de 60 e 80, um início de democratização dessa educação para o público feminino. Estudar, se formar e trabalhar ainda eram conquistas que poucas possuíam e na maioria das vezes, estava conectada à posição social e econômica dessa mulher ${ }^{9}$. (SILVA, 2015).

Claro que nos dias atuais, esse ingresso é bem mais constante do que antigamente, aliás, em muitos cursos, como o de Direito, a maioria dos discentes que se forma são do público feminino. Apesar de representarem pouco mais da metade das inscrições na $\mathrm{OAB}$, as mulheres ainda possuem dificuldade de chegar no topo de muitas carreiras jurídicas. A percepção dessa luta por uma presença constante acaba sendo expandida para diversos campos profissionais nos quais quantidade e qualidade, ou reconhecimento, parecem não caminharem lado a lado (NUNES, 2020).

Ao que parece, seja qual for o fenômeno, a discussão sobre o mesmo dentro da academia ainda é um dos melhores embriões não só para a troca e compartilhamento de pesquisas e produções, como também para o embasamento de ações, políticas públicas e

\footnotetext{
${ }^{9}$ Por muito tempo, a formação acadêmica foi interligada à capacidade econômica determinado sujeito ou sua família, ter um diploma era um diferencial cultural, político e econômico que poucas pessoas tinham. Levando em consideração que a própria luta feminista engloba o reconhecimento dessas mulheres diante de suas posições enquanto sujeito de direitos, a referência acadêmica feminina perpassa por recortes históricos como a emancipação das mulheres civilmente, a conquista do voto, o direito de estudar, a pílula anticoncepcional e o ingresso no mercado de trabalho (SILVA, 2015).
} 
apoios de mercado. Chamar a atenção para como e por quem se dá a produção acadêmica é sinalizar para um debate que pode até em primeira mão se concentrar nos muros de universidades, faculdades e centros de ensino. Todavia, o que se quer apontar é que o tratamento e valorização da presença feminina no espaço acadêmico não é algo que estará exclusivamente estampado nas telas de computadores, murais, livros e quadros de anotações, mas sim na concretizações de seus direitos, nas quebras paradigmáticas dos modelos masculinos de produção e no enaltecimento de seus potenciais.

\section{O IMPACTO DA PRODUCAÇÃO ACADÊMICA FEMININA PELA PANDEMIA DO COVID-19}

A partir de uma pesquisa quantitativa, buscou-se analisar se as mulheres tiverem grandes consequências acadêmicas em virtude do home office, causado pelo distanciamento social que fora imposto pela pandemia do covid-19.

A análise gráfica foi realizada a partir de respostas de mulheres professoras no ensino jurídico. Os dados foram colhidos no período de 04/08/2020 a 15/09/2020, com a média de 45 respostas.

O sentimento de que o trabalhou aumentou consideravelmente é quase que unânime, conforme gráfico abaixo.
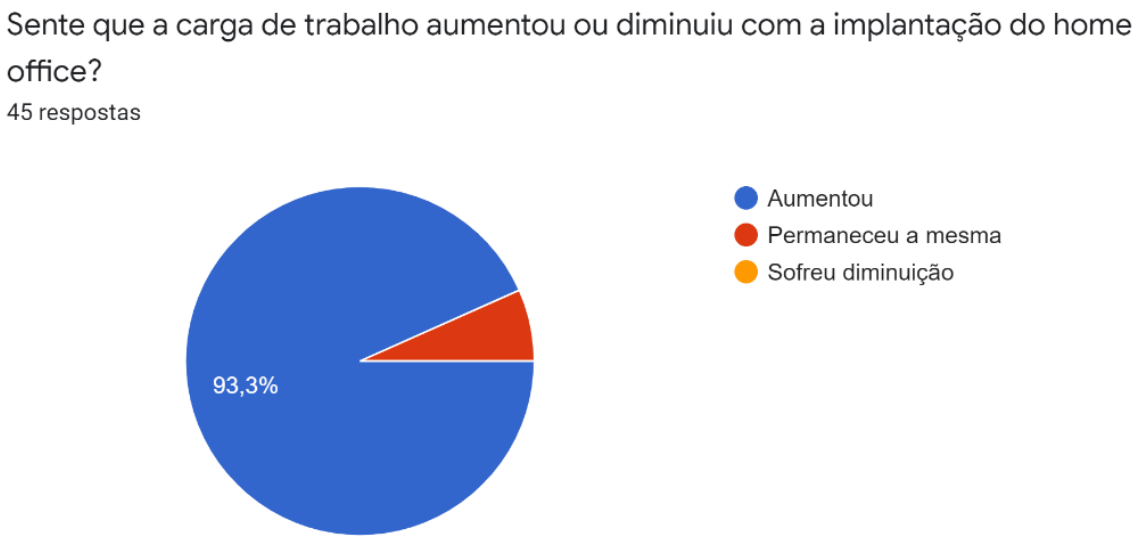

Gráfico 01

A questão do aumento da carga de trabalho acaba remetendo primeiramente, a todo o transportar de aulas, pesquisas, debates e orientações realizadas nos locais de ensino para o âmbito doméstico e toda a adaptação deste para com as novas atividades, o que era antes realizado de forma esporádica e pontual nos lares, passou a fazer parte das rotinas dessas 
mulheres. Os espaços públicos e privados se tornaram um só de modo a concatenar não só atividades laborais como as ligadas ao espaço familiar.

A reflexão aqui apresentada ao abordar a carga de trabalho, se faz mister vez que permite analisar que ao fundo o trabalho a ser considerado envolve o dito "formal" e o "informal", haja vista tradicionalmente os cuidados para com a família e o ambiente das casas ficar a cargo feminino (PORTO, 2008). Não que o home office não tenha auxiliado em larga medida a realização das responsabilidades acadêmicas, mas em alguma medida ele também impactou na atenção agora mais divida entre filhos, maridos, cozinha e limpeza da casa por exemplo.

Nesse mesmo ritmo, a elevação possui relação também com os treinamentos necessários para com a tecnologia a ser utilizada e mediada nas produções acadêmicas. Notase que nem todas as docentes e pesquisadoras possuíam toda proximidade e técnica necessárias para o manuseio de aparelhos eletrônicos concomitantes, plataformas, salas virtuais, sendo assim o empenho colocado também leva em consideração a dedicação e estudos dessas novas tecnologias para com as produções acadêmicas. Em um curto espaço de tempo, os papéis ativos e passivos para com a vida acadêmica precisaram ser revistos já que ao que parece, os modos de aula e pesquisa tradicionalmente postos já não atendem às demandas reais e sociais (DE OLIVEIRA; CORRÊA; MORÉS, 2020).

Em um primeiro momento pode-se acreditar que a implementação dessas tecnologias, mesmo em caráter emergencial, poderia ter otimizado por completo qualquer atividade feminina desempenhada, todavia é válido questionar até ponto essas inovações também solicitaram mais atenção, esforço mental, físico e psicológico dessas mulheres. Talvez não exclusivamente, mas para além dos profissionais de saúde, os que lidam com a educação também sofreram aumento no desenvolvimento de doenças ligadas à ansiedade, estresse e depressão (SILVA et al, 2020).

Além da dificuldade de adaptação ao formato remato, as mulheres tiverem o home office fatigante pela necessidade de conciliação ${ }^{10}$ com os afazeres domésticos. Na pesquisa coleta, 76,1\% das mulheres não conseguiram se ajustar à situação atípica.

Percebe que conseguiu conciliar atividades domésticas com as referentes ao trabalho?

10 “Árlempoơtass disso, as mulheres nas epideminas são cuidadoras de seus companheiros, filhos, família e comunidade. Elas têm maior risco de contágio e, se adoecerem, serão cuidadas, provavelmente, por outras mulheres (DE SOUZA; YOSHIMOTO; RIBEIRQ, 2020).

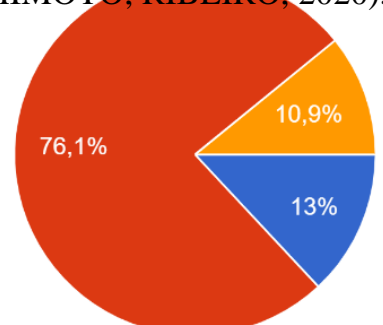


Nesse mesmo sentido, a Data folha, divulgou uma pesquisa que demonstrou que as atividades domésticas atrapalharam o home office para $64,5 \%$ das mulheres ${ }^{11}$. Afinal, conciliar filhos, aulas remotas das crianças e adolescentes, reuniões por videoconferências, problemas com conexão à internet, tarefas do lar, lecionar aulas e ainda produzir academicamente, foi bem árduo, tendo em vista a reunião no mesmo espaço e tempo de obrigações pessoais e profissionais.

Alia-se o fato ainda que $50 \%$ das mulheres que responderam ao questionário, não receberem nenhum apoio de familiares para elaboração de atividades acadêmicas.

Recebeu apoio da familia para realizar as atividades acadêmicas?

46 respostas

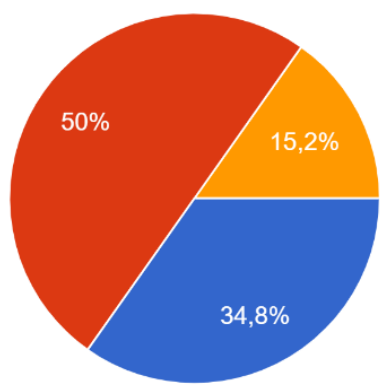

Sim

Em alguns momentos

Não

Gráfico 03

\footnotetext{
${ }^{11}$ Fonte: https://www1.folha.uol.com.br/mercado/2020/08/pesquisa-aponta-que-afazeres-domestico-dificultamhome-office-para-645-das-mulheres.shtml
} 
Até mesmo esse debate sobre ter ou não auxílio nessas atividades acadêmicas, faz pensar que novamente, se o ritmo e a produção já são vestidas de aspectos masculinos, a ideia de que a mulher consegue fazer sozinha ou "deve dar conta" perpassa esse certo abandono. Caso houvesse a presença desse auxílio, ocorreria que impacto claro em pesquisas e produções não só quantitativamente melhores, como também na própria qualidade das mesmas. A conciliação de atividades chega a ter a sugerir em um exercer mútuo e equilibrado de diversos centros de atenção, entretanto o que de fato acontece é que em alguns ou todos os pontos ocorrerá uma defasagem.

Nesse cenário de estresse, aumento de exigências e de pouca ajuda, o resultado não poderia ser outro: a redução do rendimento acadêmico das mulheres. Conforme gráfico 04, $56,5 \%$ das mulheres sentiram essa perda de produtividade.
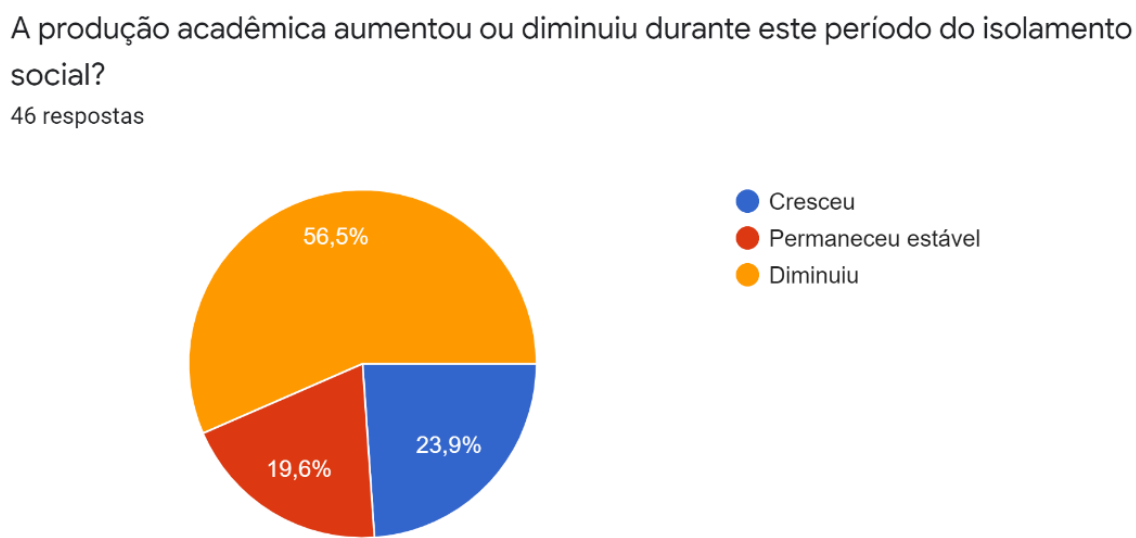

Em pesquisa divulgada pela Abril, concluiu-se que o resultado da pandemia do covid19 na quantidade de artigos científicos produzidos por mulheres foi bem negativo ${ }^{12}$. Assim, percebe-se que o distanciamento social intensificou ainda mais as desigualdades de gênero.

Apesar de não ter sido objeto do questionário aplicado, mas que simboliza a produção acadêmica feminina em tempos de COVID-19 é que cresceu o número de pesquisadoras que se debruçaram na temática da violência doméstica durante o isolamento social. Não obstante o compartilhar de sentimentos de luta e sobrevivência diante de um mundo ainda tão machista e violento, a temática abordada pode mostrar mais uma vez que escritos e produções sobre

\footnotetext{
${ }^{12}$ Fonte: https://vocesa.abril.com.br/carreira/por-que-a-producao-de-artigos-cientificos-por-mulheres-caiubrutalmente/.
} 
mulheres e realizadas por mulheres é algo que vai além da percepção do local de fala e transcende até a própria afirmação dessas pesquisadoras diante do ambiente acadêmico (DE SOUZA; YOSHIMOTO; RIBEIRO, 2020).

Por mais que tenha ocorrido reduzam na produção, impacto na conciliação de outras atividade da jornada múltipla feminina e um certo sentimento de solidão diante de tantas tarefas, a luta por espaço e respeito permanece, seja no aprendizado das tecnologias para com a pesquisa e a docência, seja no aprofundar de temáticas de gênero que só evidenciaram as segregações já existentes, ou ainda na demonstração talvez o cuidado possua uma essência feminina, a vivência acadêmica só demonstra que assim como outros campos, ali também é lugar de mulheres fortes.

\section{CONCLUSÃO}

Com o isolamento social, as pessoas foram forçadas a trabalhar, estudar e se manter em casa. Assim, foram impelidas a aderirem ao uso de ferramentas, programas e aplicativos tecnológicos para se tornarem operantes, ativos e permanecer no mercado de trabalho.

Nesse cenário, pela ausência de aperfeiçoamento, docentes transplantaram as práticas do ambiente presencial para o ambiente virtual. A carga horária foi um desafio, pois a temporalidade do formato físico é bem diferente da temporalidade virtual. O tempo atrás da tela de um computador ou smartphone gera um cansaço maior.

Assim, pensar o papel da sala de aula nesse momento é importante ao analisar o ensino jurídico nesse contexto. Cabe ao professor garantir a manutenção do projeto de investimentos dos alunos e/ou garantir também a saúde mental desses discentes.

A sensibilidade é ponto fundamental, pois não se pode exigir de um aluno que divide o quarto com vários irmãos a participação efetiva em sala de aula. Assim, o que se vê é que as desigualdades foram ainda mais afloradas e compete ao professor agir com sensibilidade nesse momento tão atípico.

Claro que a manutenção do ensino em geral para além do não comprometimento total dos calendários, abarca também a continuidade de empregos, projetos, relações interpessoais e a função socializadora e formadora da educação, mas a manutenção do ensino jurídico talvez possua ligação com as mudanças advindas desse novo panorama nacional e mundial que inevitavelmente acirram ou amenizam alguns tipos de conflitos. A formação de um bom 
profissional perpassa também pela demonstração da teoria e da prática e como esse discente olha e interpreta o Direito enquanto transformador ou pelo menos um dos agentes de mudança de paradigmas.

Desigualdade de acesso à internet, tempo de aula, desenvolvimento de atividades a partir do uso das tecnologias, foram alguns dos gargalos encontrados.

Além da dificuldade de implementar metodologias ativas na aprendizagem do ensino jurídico, as professoras mulheres foram ainda mais impactadas. Tendo em vista não só a hierarquização e divisão sexista de trabalho existentes nos espaços de desenvolvimento científico, as mesmas se depararam como uma carga e acúmulo de papéis que interferem direta e indiretamente em suas produções acadêmicas.

Parece ser muito comum a conciliação de demandas para o público feminino, conciliação esta que por vezes é exigida mesmo que de forma sutil por parte da sociedade, de modo a considerar que ser mulher é ser boa como mãe, esposa, filha, amiga, professora, pesquisadora e discente, por exemplo. A sobreposição de papéis parece ter uma aceitação naturalizada ainda em valores tradicionais, conservadores e machistas de como, onde e quando a mulher pode ou não estar presente.

A pandemia da COVID-19 apenas sinalizou para desigualdades há muito tempo existentes não só na educação e ensino jurídico brasileiro, como também na sociedade. Homens e mulheres recebem tratamento diferenciado quando o assunto é produção acadêmica, valorização das pesquisas, ingresso nas universidades, papéis assumidos nos lares, exercícios parentais e repartição de atividades domésticas. Por óbvio, isto não configura o quadro geral de todas as famílias, entretanto sinaliza para um ainda perpetuar de discriminações e segregações que afetam a mulher contemporânea. Em muito se avançou e se conquistou ao longo dos últimos anos, mas são em situações atípicas e emergenciais como a pandemia do Corona vírus, que fica cada vez mais evidente o quão se faz também urgente o reconhecimento feminino em todos os espaços.

\section{REFERÊNCIAS}

BRASIL. Planalto. Lei $\mathbf{n}^{\mathbf{0}}$ 13.979, DE 6 DE FEVEREIRO DE 2020. Presidência da República. Disponível em: <http://www.planalto.gov.br/ccivil_03/_ato20192022/2020/lei/L13979.htm>. Acesso em 13/09/2020. 
BRASIL, Ministério da Educação. Portaria $\mathbf{n}^{\circ}$ 1.428, de 28 de dezembro de 2018. Dispõe sobre a oferta, por Instituições de Educação Superior - IES, de disciplinas na modalidade a distância em cursos de graduação presencial. Disponível em: < http://portal.mec.gov.br/index.php?option=com_docman\&view=download\&alias=108231portaria-1428\&category_slug=fevereiro-2019-pdf\&Itemid=30192?. Acesso em 14/09/2020.

CARDOSO, Roberta Teles. O direito à educação, a qualidade do ensino jurídico e o acesso à justiça. 2007. Disponível em: http://repositorio.ufc.br/handle/riufc/12509. Acesso em 04 de setembro de 2020.

COELHO, Mônica. Por uma Educação sem Fronteiras e em Tempos de PandemiaDemocrática, Pública e de Qualidade. Journal of Social Pedagogy, v. 9, n. 1, 2020.

DA GAMA, Guilherme Calmon Nogueira; NEVES, Thiago Ferreira Cardoso. Direito privado emergencial: $O$ regime jurídico transitório nas relações privadas no período da pandemia da Covid-19. Editora Foco, 2020

DA SILVA, Fabiane Ferreira. CONCILIANDO IDENTIDADES: MULHER, MÃE, ESPOSA, CIENTISTA.. 2013. Disponivel em: http://www.fg2013.wwc2017.eventos.dype.com.br/resources/anais/old_20/1384792028_ARQ UIVO_FabianeFerreiradaSilva.pdf. Acesso em 12 de setembro de 2020.

DE OLIVEIRA, Raquel Mignoni; CORRÊA, Ygor; MORÉS, Andréia. Ensino remoto emergencial em tempos de covid-19: formação docente e tecnologias digitais. Revista Internacional de Formação de Professores, v. 5, p. e020028-e020028, 2020. Disponível em: https://periodicoscientificos.itp.ifsp.edu.br/index.php/rifp/article/view/179. Acesso em 20 de setembro de 2020

DE SOUZA, Solange Aparecida Monteiro; YOSHIMOTO, Eduardo; RIBEIRO, Paulo Rennes Marçal. A produção acadêmica sobre a questão da violência contra a mulher na emergência da pandemia da covid-19 em decorrência do isolamento social. DOXA: Revista Brasileira de Psicologia e Educação, v. 22, n. 1, 2020. Disponível em: https://periodicos.fclar.unesp.br/doxa/article/view/13976/9399. Acesso em 20 de setembro de 2020.

FEFERBAUM, Marina; KLAFKE, Guilherme. Ensino Jurídico na quarentena (II): o que vivemos e aprendemos até aqui. Revista Consultor Jurídico. Publicado em 29 de maio de 2020. Disponível em: https://www.conjur.com.br/2020-mai-29/feferbaum-klafke-ensinojuridico-quarentena-parte-ii. Acesso em 04 de setembro de 2020

; LIMA, Stephane HB. Formação jurídica e novas tecnologias: relato de uma aprendizagem experiencial em direito. Revista Opinião Jurídica (Fortaleza), v. 18, n. 28, p. 2020. 145-162, Disponível em: 
https://periodicos.unichristus.edu.br/opiniaojuridica/article/view/2740/1103. Acesso em 04 de setembro de 2020

GHIRARDI, José Garcez. O instante do encontro: questões fundamentais para o ensino jurídico. 2012. Disponível em: https://bibliotecadigital.fgv.br/dspace/handle/10438/10303. Acesso em 04 de setembro de 2020.

HARARI, Yuval Noah. Na batalha contra o coronavírus, faltam líderes. Tradução Odorico Legal. São Paulo: Companhia das Letras, 2020. (Kindle)

KOVALESKI, Nadia Veronique Jourda. Relações de gênero entre docentes dos Programas de Pós-Graduação da Universidade Tecnológica Federal do Paraná (UTFPR) e da Universidade Tecnológica de Compiègne (UTC-França): um estudo comparativo das carreiras de homens e mulheres. 2013. Disponivel em: http://repositorio.utfpr.edu.br:8080/jspui/bitstream/1/709/1/CT_PPGTE\%20_D_Kovaleski\%2 c\%20Nadia\%20Veronique\%20Jourda_2013.pdf. Acesso em 12 de setembro de 2020

MALCOM, Shirley. In: Mulheres na ciência e na engenharia: um imperativo global. Encontro Nacional de Núcleos e Grupos de Pesquisa. Pensando Gênero e Ciências. p. 121135. Brasília. 2006. Disponível em: https://www.gov.br/mdh/pt-br/navegue-portemas/politicas-para-mulheres/arquivo/sobre/publicacoes/publicacoes/2006/encontrogenero.pdf\#page=63. Acesso em 12 de setembro de 2020 .

NUNES, Wálter. Advogadas criam escritórios só de mulheres em busca de espaço no direito. Folha Mulher. Folha de São Paulo. Publicado em 08 de março de 2020. Disponível em: https://www1.folha.uol.com.br/poder/2020/03/advogadas-criam-escritorios-so-de-mulheresem-busca-de-espaco-no-direito.shtml. Acesso em 15 de setembro de 2020.

PORTO, Dora. Trabalho doméstico e emprego doméstico: atribuições de gênero marcadas pela desigualdade. Revista Bioética - 16 (2), 287-303. Disponível em: https://revistabioetica.cfm.org.br/index.php/revista_bioetica/article/view/74/77.. Acesso em 20 de setembro de 2020

RAMALHO, Halleyde Souza. O desafio do ensino no curso de direito em tempos de transição paradigmática. $2019 . \quad$ Disponível em: https://bibliodigital.unijui.edu.br:8443/xmlui/handle/123456789/6127. Acesso em 04 de setembro de 2020.

RODRIGUES, Horácio Wanderlei. Educação superior em tempos de pandemia: direito temporário aplicável e seu alcance. Revista de Pesquisa e Educação Jurídica, v. 6, n. 1, p. 62-82, 2020. Disponível em: https://indexlaw.org/index.php/rpej/article/view/6526. Acesso em 04 de setembro de 2020 
SANTOS, Boaventura de Sousa. A cruel pedagogia do vírus. Biblioteca Nacional de Portugal. Coimbra, Portugal. Edições Almedina. 2020

SANTOS, Vívian Matias dos. Uma "perspectiva parcial" sobre ser mulher, cientista e nordestina no Brasil. Rev. Estud. Fem., Florianópolis, v. 24, n. 3, pág. 801-824, dezembro de 2016. Disponível em <http://www.scielo.br/scielo.php?script=sci_arttext\&pid=S0104026X2016000300801\&lng=en\&nrm=iso>. Acesso em 12 de setembro de 2020.

SILVA, Andrey ferreira da et al. Saúde mental de docentes universitários em tempos de pandemia. Physis: Revista de Saúde Coletiva, v. 30, p. e300216, 2020. Disponivel em: https://www.scielosp.org/article/physis/2020.v30n2/e300216/pt/. Acesso em 20 de setembro de 2020

SILVA, Emanuely Arco Iris. Ciência no feminino: um estudo sobre a presença da mulher docente na pós-graduação da UFPE. 2015. Dissertação de Mestrado. Universidade Federal de Pernambuco. Disponível em: https://repositorio.ufpe.br/bitstream/123456789/17272/1/DISSERTA\%c3\%87\%c3\%830\%20 EMANUELY_ARCO\%20IRIS\%20COMPLETA.pdf. Acesso em 15 de setembro de 2020.

VELHO, I. Prefácio. In: SANTOS, L; ICHIKAWA, E. Y; CARGANO, D.F. (Orgs). Ciência, tecnologia e gênero: desvendando o feminino na construção do conhecimento. Londrina: IAPAR, 2006. 